\title{
Effect of Inter-granular Void Ratio on Volume Compressibility and Undrained Shear Response of Base-sand and Natural Silty- sand of Kutch
}

\author{
Majid Hussain ${ }^{1, *}$ and Ajanta Sachan ${ }^{1}$ \\ ${ }^{1}$ Indian Institute of Technology Gandhinagar, Civil Engineering, India
}

\begin{abstract}
In this article, effect of inter-granular void ratio $\left(e_{g}\right)$ on the volume compressibility and undrained shear strength behaviour of a natural silty-sand and base-sand is explored. Natural silty-sand sample was collected from Fatehgarh dam in Kutch region of India and the specimens prepared were subjected to isotropically consolidated undrained compression (CIUC) triaxial tests under two scenarios. In scenario one, silty-sand collected from Fatehgarh dam was used to perform CIUC triaxial tests at in-situ density. However, scenario two was based on CIUC triaxial tests on base-sand, which was extracted from Fatehgarh dam silty-sand soil by removing fines. It was ensured that the two specimens (silty-sand, basesand) had the same void ratio $(e=0.704)$ but different inter-granular void ratios $\left(e_{\text {-silty-sand }}=1.156\right.$ and $e_{g}$ base-sand $=0.704)$. Volume compressibility during isotropic consolidation phase of specimens was strongly reduced in the base-sand as compared to silty-sand. The undrained shear response of base-sand showed an increase in peak deviatoric stress by a factor of 1.8, 1.6 and 1.7 as compared to silty-sand at an initial effective confining pressure of $100 \mathrm{kPa}, 200 \mathrm{kPa}$ and $300 \mathrm{kPa}$ respectively. The angle of friction mobilized at peak deviatoric stress and the work done per unit volume increased with the decrease in the inter-granular void ratio $(e g)$, although the void ratio $(e)$ was same.
\end{abstract}

\section{Introduction}

Stress-strain behaviour and effective stress path response of sandy soils under undrained conditions could be classified in three typical responses as introduced by Castro [1]: strain softening (SS), limited strain softening (LSS) and strain hardening (SH). SS and LSS lead to liquefaction and limited liquefaction respectively and can be observed in loose saturated cohesionless soils. SH is an attribute of highly dilative soils and does not lead to liquefaction. The type of response exhibited by a soil mass depends on a number of factors viz current material state, stress state, and boundary conditions. State parameter $(\psi)$ defined using void ratio $(e)$ has been used previously to predict the mechanical behaviour of sands and clays under the framework of critical state soil mechanics (CSSM) at different loading and boundary conditions. It is now well established that the CSSM framework has been effective in predicting the undrained behaviour of sands. As such, before 1960's undrained behaviour of clean sands was assertively used to understand the liquefaction aspects of soils. However, since 1960s it has been recognized that the presence of fines both plastic and non-plastic has a strong impact on liquefaction behaviour of sands. Recent studies reported a decrease in liquefaction resistance with the addition of fines till a limiting fines content but then with the further addition of fines liquefaction resistance increased. However, this behaviour could not be explained under the CSSM framework due to a number of challenges. This was attributed to the non-uniqueness of the locus of the critical states (critical state line, CSL) in the $e-\ln \left(p^{\prime}\right)$ plane; where $e$ and $p^{\prime}$ are the void ratio and mean effective pressure respectively. The CSL was found to be dependent on the fines content and was different for each percentage of fines. This, in turn, rendered CSSM less proficient in determining the behaviour of silty-sands if the $e$ was used to define $\psi$. Similar to the effect of fines on liquefaction characteristics, the effect of fines on the CSL and isotropic compression line (ICL) was reported to be diverse among many research groups. Been and Jefferies [2] reported that the slope of CSL lines in the $e$ $\ln \left(p^{\prime}\right)$ increased with the fines content. Few studies reported that CSL moved downward in $e-\ln \left(p^{\prime}\right)$ till $\sim 30 \%$ fines content (FC) and then moved upwards with the further addition of fines. The unusual "reverse sand behaviour" of silty-sands reported by Lade and Yamamuro [3] and later observed by others could not be explained under the CSSM framework using void-ratio based state parameter. Both the compressibility as well as undrained shear strength were significantly affected by the presence of fines. CSL and ICL were determined to be non-unique for sands with different fines content.

To overcome the different challenges faced while using CSSM in predicting the undrained behaviour of silty-sands the concept of the inter-granular void ratio $\left(e_{g}\right)$ was proposed. It was computed by considering fines

* Corresponding author: majid.hussain@iitgn.ac.in 
as voids (Eq.1) and had been used to understand the undrained behaviour of transitional geo-materials.

$$
e_{g}=[e+F C] /[1-F C]
$$

where $e$ is the void ratio and $\mathrm{FC}$ the fines content.

This article aims to experimentally investigate the effect of the inter-granular void ratio on isotropic compression and undrained shear behaviour of a natural silty-sand and base-sand. The fines content of the Fatehgarh dam silty-sand was assumed to be less than the threshold fines content $\left(\mathrm{FC}_{\mathrm{th}}\right)$ to maintain the soil fabric as a fines-in-sand matrix.

\section{Material properties, specimen preparation, and experimental program}

Medium dense natural silty-sand collected from inside the reservoir at 50 meters away from the upstream toe of Fatehgarh dam at a depth of $2.5 \mathrm{~m}$ was used in the current study. Grain size distribution of natural silty-sand, basesand, and fines is shown in Figure 1. Coarse fraction was dominated by fine sand constituting $51.6 \%$ of the total soil mass. Isotropically consolidated undrained compression (CIUC) triaxial tests were performed on specimens of $50 \mathrm{~mm}$ diameter and $100 \mathrm{~mm}$ height $(H / D=2)$. Specimens were prepared at an in-situ dry density of $15.5 \mathrm{kN} / \mathrm{m}^{3}$ (void ratio, $e=0.704$ ) and moisture content of $8 \%$ using moist tamping technique. Saturation of the specimens was accomplished in three stages: $\mathrm{CO}_{2}$ flushing, water flushing, and back pressure saturation. Deformation controlled CIUC triaxial tests were performed at three initial effective confining pressures $\left(p^{\prime}{ }_{c}\right)$ for each of the two materials; natural silty-sand and base-sand. Following saturation, specimens were subjected to isotropic consolidation at $p^{\prime}{ }_{c}$ of $100 \mathrm{kPa}, 200 \mathrm{kPa}$, and $300 \mathrm{kPa}$. Isotropically consolidated specimens were further subjected to undrained shearing at a strain rate of $0.1 \%$ per minute.

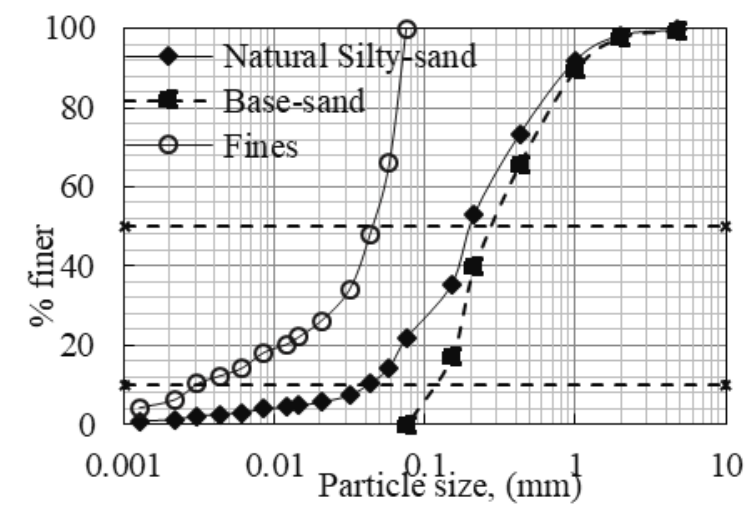

Fig. 1. Grain size distribution of Fatehgarh dam soil

\section{Results and discussion}

Very loose sands and loose silty-sands have high compressibility and small undrained shear strength. The undrained shear strength response of sands and siltysands have been expressed as a function of the void ratio with the assumption that there is no distinction between the coarse sand grains and fines and both take equal part in force chain network. However, recent studies show the different effect of fines on the undrained shear strength behaviour of sands. The current experimental study was undertaken to investigate the effect of the $e_{g}$ on the volumetric compressibility $\left(\mathrm{m}_{\mathrm{v}}\right)$ and undrained monotonic shear behaviour of poorly graded base-sand (SP) and natural silty-sand (SM).

\subsection{Effect of the inter-granular void ratio on volume compressibility}

The response of natural silty-sand and the base-sand specimens under isotropic consolidation at three initial effective confining pressures $\left(p^{\prime}{ }_{c}\right)$ of $100 \mathrm{kPa}, 200 \mathrm{kPa}$, and $300 \mathrm{kPa}$ is shown in Figure 2. Volumetric strains $\left(\varepsilon_{v}\right)$ of both the natural silty-sand and base-sand were observed to increase with an increase in $p^{\prime}{ }_{c}$. This could be attributed due to the pressure-dependent constitutive material behaviour of soil. At a given $p^{\prime}{ }_{c}$ the presence of smaller silt particles created metastable inter-particle soil structure, which being collapsible in nature, resulted in higher volumetric strains in natural silty-sand specimens. The volumetric compressibility of natural silty-sand specimens was evaluated to be more than 1.5 times as that of base-sand specimens at the same $e$ but lower $e_{g}$ (Table 1). The ratio increased to 2.75 at $300 \mathrm{kPa}$ which could be due to the larger movement of the silt particles into the voids between the sand particles. In the case of base-sand specimens, the higher number of sand-to-sand contacts might have led to lower compressibility. Lower $e_{g}$ in the base-sand as compared to the natural silty-sand captured the trend observed in volumetric response during isotropic consolidation. However, the same trend could not be captured with the state parameter as a function of the global void ratio $(e)$.

In terms of $e$, the specimens of natural silty-sand and base-sand had void ratios very close to each other. However, there was a considerable difference in the volumetric response which was unexpected. The significant difference between the $e_{g}$ of the two types of specimens could explain the observed behaviour. It also captured the "reverse sand behaviour" and could be attributed to the increased $e_{g}$ with the addition of fines leading to lower number of sand-to-sand contacts and higher $m_{v}$. The compressibility of natural silty-sand specimens at three $p^{\prime}{ }_{c}$ was observed to be much higher as compared to base-sand specimens (Table 1). It was further increased as $p^{\prime}{ }_{c}$ increased from $100 \mathrm{kPa}$ to 300 $\mathrm{kPa}$, however in the case of base-sand it was found to decrease slightly. Particle size disparity $\left\{\mathrm{D}_{50 \text { (sand) }} / \mathrm{D}_{50 \text { (fines) }}\right\}$ as could be calculated from Figure 1 was nearly 6.5. Therefore, very few fines could be expected to participate in the load transfer, and most of the fines could move into the voids of coarser particles leading to the larger compressibility of silty-sand specimens. In the case of base-sand specimens there was no such movement, and the specimens exhibited lower compressibility as compared to natural silty-sand specimens. 


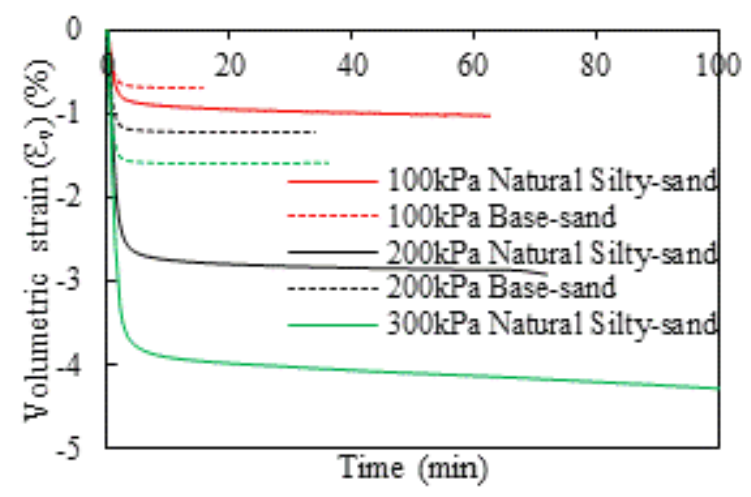

Fig. 2. Relationship between volumetric strain and time under isotropic consolidation at constant $e$ and different $e_{\mathrm{g}}$

Table 1. Effect of initial $e_{g}$ on isotropic $m_{v}$

\begin{tabular}{|c|c|c|c|}
\hline \multirow{2}{*}{$\begin{array}{c}\mathrm{p}^{\prime}{ }_{\mathrm{c}} \\
(\mathrm{kPa})\end{array}$} & $\begin{array}{c}\text { Volume compressibility }\left(\mathrm{m}_{\mathrm{v}}\right)\left(* 10^{-4} / \mathrm{kPa}\right) \\
\mathrm{m}_{\mathrm{v}(\mathrm{nss})}, \mathrm{e}_{\mathrm{g}}=1.156\end{array}$ & $\begin{array}{c}\text { Base-sand, } \\
\mathrm{m}_{\mathrm{v}(\mathrm{bs})}, \mathrm{e}_{\mathrm{g}}=0.704\end{array}$ & $\begin{array}{c}\text { Ratio } \\
\mathrm{m}_{\mathrm{v}(\mathrm{nss})} / \mathrm{m}_{\mathrm{v}(\mathrm{bs})}\end{array}$ \\
\hline 100 & 1.03 & 0.70 & 1.47 \\
\hline 200 & 1.46 & 0.62 & 2.37 \\
\hline 300 & 1.47 & 0.53 & 2.75 \\
\hline
\end{tabular}

\subsection{Effect of the inter-granular void ratio on undrained shear strength behvaiour}

Very loose sands and loose silty-sands exhibit fragile response under imposed undrained shear deformations. The intense strain softening is preceded by solid-fluid instability and subsequently leads to static liquefaction. Figure 3 shows the stress-strain and excess pore water pressure response of the two geo-materials. All the specimens exhibited intense strain-softening with very large undrained brittleness, $I_{b}=\left(q_{\text {peak }}-q_{\text {min }}\right) / q_{\text {peak }}$. Both the natural silty-sand and base-sand specimens showed intense liquefaction at all the three $p_{c}^{\prime}$ except at $300 \mathrm{kPa}$. However, $q_{\text {peak }}$ was found to be higher by a factor of more than 1.6 in the case of base-sand specimens. Although both the silty-sand and sand specimens had a similar $e$ at the end of consolidation at each $p_{c}^{\prime}$, the significant variations in $q_{\text {peak }}$ can not be attributed to the insignificant difference in the $e$ of these specimens. However, the observed behaviour could be attributed to the large difference in $e_{g}$. The large number of stronger sand-to-sand contacts in base-sand specimens resulted in the mobilisation of higher $q_{\text {peak }}$.

Natural silty-sand and base-sand specimens exhibited static liquefaction at the initial $p_{c}^{\prime}$ of $100 \mathrm{kPa}$ and 200 $\mathrm{kPa}$. At $p^{\prime}{ }_{c}$ of $100 \mathrm{kPa}$, the natural silty-sand and basesand specimens attained $q_{p e a k}$ values of $43 \mathrm{kPa}$ and 76 $\mathrm{kPa}$ respectively at axial strain $\left(\varepsilon_{a}\right)$ levels of $0.78 \%$ and $0.70 \%$ respectively. After attaining $q_{\text {peak }}$, both the specimens exhibited response similar to that of flow liquefaction. The specimens exhibited a similar behavior at $p^{\prime}{ }_{c}$ to be $200 \mathrm{kPa}$, with $q_{\text {peak }}$ values of $93 \mathrm{kPa}$ and 150 $\mathrm{kPa}$ being attained at $\varepsilon_{a}$ to be $0.77 \%$ and $0.70 \%$ respectively. An interesting feature was observed in both the natural silty-sand and base-sand specimens at $p_{c}^{\prime}$ of $100 \mathrm{kPa}$ and $200 \mathrm{kPa}$ with the specimens attaining $q_{\text {min }}$ at nearly same $\varepsilon_{a}$ of $8.1 \%$. It indicated high vulnerability of both geo-materials to static liquefaction. The stress ratio $\left(\eta=q / p^{\prime}\right)$ at $q_{\text {peak }}$ (Table 2) was found to be lower in natural silty-sand specimens as compared to that of basesands specimens. This revealed that the friction angle mobilized at the $q_{\text {peak }}$ in the case of silty-sand specimens was lower as compared to that of base sand specimens. When this behavior was analyzed in the context of void ratio, it could not be captured as both have similar $e$. In terms of the $e_{g}$, the higher mobilized friction angle in the case of base-sand was observed due to the lower $e_{g}$ leading to larger and stronger sand-to-sand contacts. In the case of silty-sand specimens, $\eta$ at $q_{\text {peak }}$ was found to decrease with increase in $p_{c}^{\prime}$. This could be attributed to the response observed in compressibility behaviour of silty-sand specimens, which increased with increasing $p_{c}^{\prime}$. Such behaviour in $\eta$ was not observed in base-sand specimens and was also in agreement with the compressibility behaviour. With insignificant variation in $e$, large difference in $\eta$ could not be justified except that $e_{g}$ was adopted as a comparison basis. With fines content less than the threshold value, the participation and contribution of fines in the force chains was meagre, but they did contribute to the void ratio (e) significantly. Therefore, $e_{g}$ provided a better representation of the nature of the contact density of active particles, whereas $e$ ceased to represent the proportion of active particle contacts.

The response of the specimens at $p_{c}^{\prime}$ equal to $300 \mathrm{kPa}$ was slightly different as compared to that at $100 \mathrm{kPa}$ and $200 \mathrm{kPa}$ (Fig. 3a). Natural silty-sand and base-sand specimens attained $q_{\text {peak }}$ values of $134 \mathrm{kPa}$ and $231 \mathrm{kPa}$ respectively at slightly higher $\varepsilon_{a}$ of $0.75 \%$ and $0.95 \%$ respectively. The specimens also exhibited higher steady-state deviatoric stress $\left(q_{\min }\right)$ as compared to that of the specimens at $100 \mathrm{kPa}$ and $200 \mathrm{kPa}$ respectively. This could be attributed to the relatively lower void ratio, both $e$ and $e_{g}$, at the end of consolidation at $300 \mathrm{kPa}$. However, base-sand specimen at $300 \mathrm{kPa}$ exhibited much higher $q_{\min }(41.1 \mathrm{kPa})$ as compared to the natural silty-sand specimen with the corresponding $q_{\min }$ of 12.8 $\mathrm{kPa}$. Thus, the failure mode in silty-sand and base-sand specimens at $300 \mathrm{kPa}$ was different with former failing in flow liquefaction mode whereas later one exhibited limited liquefaction. The large variation in $q_{p e a k}$ and $q_{\min }$ exhibited by the specimens of silty-sand and base-sand could not be explained by $e$ as both the specimens had similar $e$ and further, it did not take into account the nonactive role of fine silt particles (Table 2). The mechanical response of granular mixes was controlled by the critical combination of inter-granular and interfine contacts. However, at $\mathrm{FC}$ near to the $\mathrm{FC}_{\text {th }}$ fines play an inactive role in force transfer, and the coarser sand particles constituted majority of the active force chains. It could be taken into account by using $e_{g}$ as an indicial parameter rather than $e$. The void ratios $(e)$ indicated in Figure $3 \mathrm{a}$ are after consolidation at respective initial effective confining pressures with the corresponding $e_{g}$ presented in Table 2.

Excess pore water pressure $(\Delta u)$ response of the natural silty-sand and base-sand specimens exhibited 
behaviour typical to that of very loose sands and loose silty-sands with $\Delta u$ attaining values nearly equal to $p^{\prime}{ }_{c}$ of $100 \mathrm{kPa}$ and $200 \mathrm{kPa}$ (Fig. 3b). Ultimate $\Delta u$ for both the silty-sand and base-sand specimens was same but in the early stages of shearing silty-sand specimens exhibited $\Delta u$ generation at a faster rate (Fig. $3 \mathrm{~b}$ ). This could be the reason for the higher undrained fragility of silty-sands. For all the specimens at $100 \mathrm{kPa}$ and $200 \mathrm{kPa}, \Delta u$ attained plateau at around $\varepsilon_{a}$ to be $8 \%$ and which was coincidental with the attainment of $q_{\min }$. For the specimens at $300 \mathrm{kPa}, \Delta u$ response exhibited by the natural silty-sand was higher than that of the base-sand throughout the shear deformation. At very large $\varepsilon_{a}(\approx 25$ $\%$ ), silty-sand specimens exhibited $\Delta u$ equal to $299 \mathrm{kPa}$ whereas corresponding $\Delta u$ attained by the base-sand specimens was $284 \mathrm{kPa}$. The difference of $15 \mathrm{kPa}$ in $\Delta u$ and $28.3 \mathrm{kPa}$ in $q_{\min }$ could not be due to the tiny difference in $e$ but might be due to the significant difference in $e_{g}$.
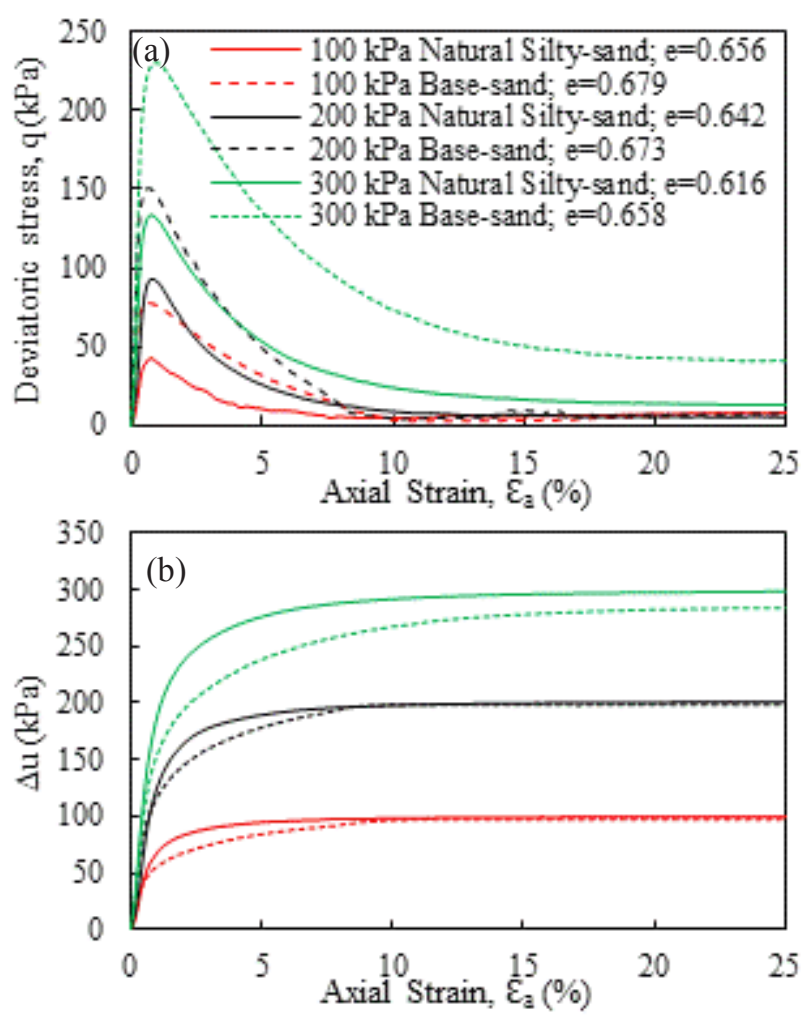

Fig. 3. Mechanical response of natural silty-sand and base-sand under undrained monotonic loading. (a) Stress-strain relationship, (b) Excess pore water pressure response.

Very large undrained fragility or liquefaction susceptibility of the silty-sand specimens at pressures amounting to $300 \mathrm{kPa}$ besides $100 \mathrm{kPa}$ and $200 \mathrm{kPa}$ could be better related to the $e_{g}$ rather than $e$. It could be attributed to the fact that at $\mathrm{FC}$ less than or near to $\mathrm{FC}_{\text {th }}$ and higher particle size disparity $(>6.5)$, the contribution of fines to the inter-particle force chain network was not significant. The presence of fines increased the number of metastable inter-particle contacts that led to higher compressibility, low undrained shear strength, higher undrained fragility and subsequently to static liquefaction (Fig. 4). The force transfer in base-sand occurs through stronger sand-to-sand contacts whereas in silty-sand few fragile sand-silt contacts are also a part of force chain. Intense post peak strain softening in both the specimens of natural silty-sand and base-sand at all the three $p^{\prime}{ }_{c}$ of $100 \mathrm{kPa}, 200 \mathrm{kPa}$, and $300 \mathrm{kPa}$ was due to the higher void ratio both $e$ and $e_{g}$.

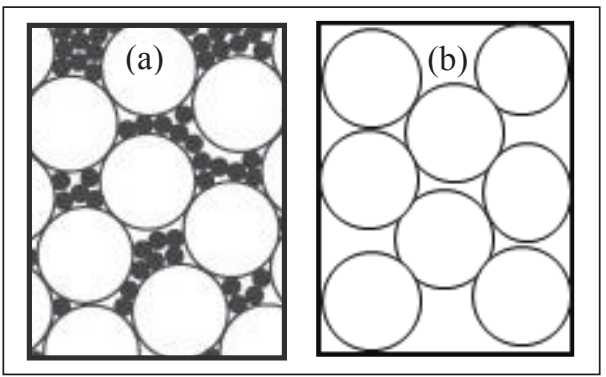

Fig. 4. Microstructure in (a) Silty-sand (b) Base-sand

\subsection{Effect of inter-granular void ratio on effective stress path behaviour}

Variation of deviatoric stress with effective mean pressure during undrained shearing is best represented by the effective stress path (ESP) in $q-p^{\prime}$ stress space. The evolution of $p^{\prime}$ and $q$ during undrained shearing reflects the nature and magnitude of $\Delta u$ changes as the stress states evolve. Figure 5 shows the ESP response of natural silty-sand and base-sand specimens at three $p^{\prime}{ }_{c}$ of $100 \mathrm{kPa}, 200 \mathrm{kPa}$, and $300 \mathrm{kPa}$. ESPs started at initial $p^{\prime}{ }_{c}$, evolved rapidly to the peak and then descended to the stress origin at all the three $p^{\prime}{ }_{c}$ for both the natural silty-sand and base-sand specimens. However, $q_{\text {peak }}$ attained at a given $p^{\prime}{ }_{c}$ was observed to be strongly dependent on the nature of the specimen: natural siltysand and base-sand. Peak deviatoric stress achieved by the base-sand specimens was more than 1.6 times like that by the silty-sand specimens.

This behavior could be attributed to the lower intergranular void ratio of base-sand specimens rather than to the small difference in $e$. Lower $e_{g}$ ensured larger and stronger sand-to-sand contacts leading to higher strength. During very early stages of shear deformation, the silt particles in silty-sand might have started to move into the voids of coarser sand particles leading to fragile compressible response. This further led to higher $\Delta u$ generation in silty-sand specimens and was evident in both pore pressure (Fig. 3b) and effective stress path response (Fig. 5). ESP for base-sand specimens was observed to evolve nearly vertically during very early stages of undrained shearing exhibiting higher strength. However, in case of silty-sand specimens, the collapsible metastable inter-particle structure induced by smaller silt particles led to the deviation of the ESP from being vertical although both silty-sand and base-sand had a similar void ratio. This further revealed that $e_{g}$ might give a better idea about the mechanical response of granular mixes as compared to $e$. The line joining the $q_{\text {peak }}$ of the ESPs and the stress origin is known as instability line (IL). The concept of $I L$ is mostly applied to the very loose and loose granular soils undergoing intense strain softening during undrained shearing. It 
represents the upper bound of the stress states that are stable under undrained conditions. Any stress state above $I L$ is unconditionally unstable under undrained boundary conditions. The ILs for natural silty-sand and base-sand specimens were determined. With similar $e$, the two types of specimens exhibited significant difference in the slope of their $I L \mathrm{~s}$. The slope of $I L$ corresponding to natural silty-sands specimens was evaluated to be 35.5 degrees whereas it was found to be 45.5 degrees for base-sand specimens.

Table 2. Variation of stress ratio $\left(\eta=q / p^{\prime}\right)$ at peak $q_{p e a k}$ and $q_{\min }$ with after consolidation inter-granular void ratio

\begin{tabular}{|c|c|c|c|c|c|c|c|c|c|c|}
\hline $\boldsymbol{p}_{\boldsymbol{c}} \boldsymbol{c}_{\boldsymbol{c}}(\boldsymbol{k P a})$ & & \multicolumn{4}{|c|}{ Natural silty-sand } & \multicolumn{4}{c|}{ Base-sand } \\
\hline & $e_{g}$ & $\boldsymbol{q}_{\text {peak }}$ & $\boldsymbol{\eta}=\boldsymbol{q}_{\text {peak }} / \boldsymbol{p}^{\prime}$ & $\boldsymbol{q}_{\boldsymbol{m i n}}$ & $\boldsymbol{\eta}=\boldsymbol{q}_{\boldsymbol{m i n}} / \boldsymbol{p}^{\prime}$ & $e_{g}$ & $\boldsymbol{q}_{\text {peak }}$ & $\boldsymbol{\eta}=\boldsymbol{q}_{\text {peak }} / \boldsymbol{p}^{\prime}$ & $\boldsymbol{q}_{\boldsymbol{m i n}}$ & $\boldsymbol{\eta}=\boldsymbol{q}_{\boldsymbol{m i n}} / \boldsymbol{p}^{\prime}$ \\
\hline 100 & 1.096 & 42.9 & 0.78 & 4.6 & 1.3 & 0.679 & 77.7 & 1.02 & 2.7 & 0.82 \\
\hline 200 & 1.078 & 93.1 & 0.73 & 5.4 & 1.6 & 0.673 & 150.4 & 1.003 & 4.4 & 1.22 \\
\hline 300 & 1.046 & 133.6 & 0.72 & 12.8 & 2.3 & 0.658 & 230.5 & 1.02 & 41.1 & 1.38 \\
\hline
\end{tabular}

This behavior could be attributed to the lower intergranular void ratio of base-sand specimens rather than to the small difference in $e$. Lower $e_{g}$ ensured larger and stronger sand-to-sand contacts leading to higher strength. During very early stages of shear deformation, the silt particles in silty-sand might have started to move into the voids of coarser sand particles leading to fragile compressible response. This further led to higher $\Delta u$ generation in silty-sand specimens and was evident in both pore pressure (Fig. 3b) and effective stress path response (Fig. 5). ESP for base-sand specimens was observed to evolve nearly vertically during very early stages of undrained shearing exhibiting higher strength. However, in case of silty-sand specimens, the collapsible metastable inter-particle structure induced by smaller silt particles led to the deviation of the ESP from being vertical although both silty-sand and base-sand had a similar void ratio. This further revealed that $e_{g}$ might give a better idea about the mechanical response of granular mixes as compared to $e$. The line joining the $q_{\text {peak }}$ of the ESPs and the stress origin is known as instability line (IL). The concept of $I L$ is mostly applied to the very loose and loose granular soils undergoing intense strain softening during undrained shearing. It represents the upper bound of the stress states that are stable under undrained conditions. Any stress state above $I L$ is unconditionally unstable under undrained boundary conditions. The ILs for natural silty-sand and base-sand specimens were determined. With similar $e$, the two types of specimens exhibited significant difference in the slope of their $I L \mathrm{~s}$. The slope of $I L$ corresponding to natural silty-sands specimens was evaluated to be 35.5 degrees whereas it was found to be 45.5 degrees for base-sand specimens.

Friction angle mobilized at $q_{\text {peak }}$ corresponding to respective $I L$ were evaluated to be 19 degrees and 26 degrees for silty-sand and base-sand specimens respectively. The huge difference of 7 degrees in the friction angle could not be due to the minimal difference in $e$, but could be due to the significant difference in $e_{g}$ of the two types of specimens. The higher number of stable and stronger sand-to-sand contacts in base-sand resulted in higher internal friction angle as compared to that of silty-sand. Although the ESPS indicated attainment of the critical state, however a slight tendency of dilation was observed even at very large strains $\left(\varepsilon_{\mathrm{a}}=25\right.$ $\%$ ). Since the specimens exhibited intense strain softening, any small deviation in either $q$ or $p^{\prime}$ led to a

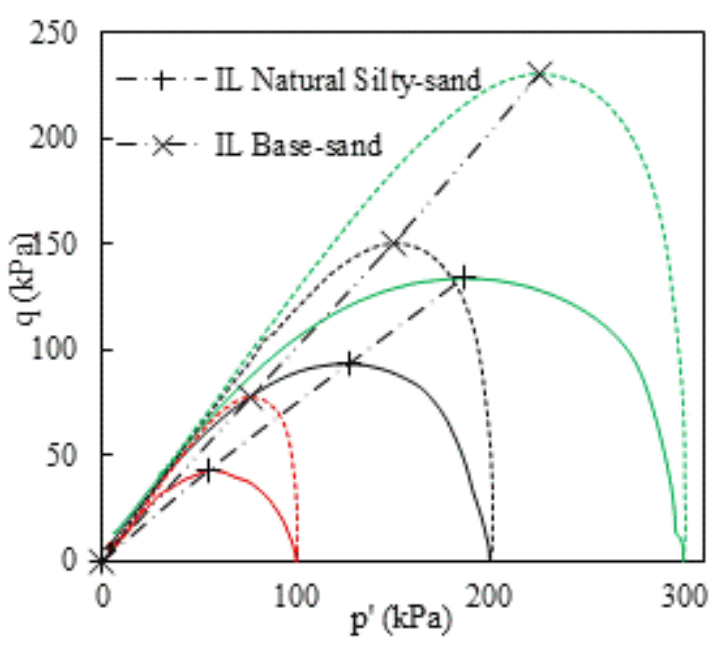

Fig. 5. Evolution of ESP at constant $e$ and different $e_{\mathrm{g}}$

huge change in stress ratio at large strain levels. However, critical state values for the two types of specimens were evaluated with extreme care by plotting $\partial p^{\prime} / \partial \varepsilon_{a}$ against $\varepsilon_{a}$ and approximate effective confining pressure at critical state $\left(p^{\prime}{ }_{c s}\right)$ was calculated. The evaluated critical state friction angle $\left(\phi_{c s}^{\prime}\right)$ for natural silty-sand and base-sand specimen were evaluated to be 33.3 degrees and 30.6 degrees respectively. Thus in the presence of $21 \%$ fines, $8.8 \%$ increase in $\phi_{c s}^{\prime}$ was observed. The increase in $\phi_{c s}^{\prime}$ at nearly same $e$, but higher $e_{g}$ could be attributed to the fact that the silt particles got sandwiched between the sand particles thereby creating a wedging effect leading to the increased shear strength of soil fabric of silt-in-sand matrix at the critical state.

\subsection{Effect of inter-granular void ratio on the work done during undrained shearing}

Work done during an imposed strain increment while deforming a material consists of two components: volumetric work $\left(W_{v}\right)$ and distortional work $\left(W_{d}\right)$. In the current study, total work done in deforming the soil elements of natural silty-sand and base-sand specimens under undrained conditions was explored. The amount of incremental work input $(\delta W)$ per unit volume was evaluated as given in Eq. 3 .

$$
\delta W=p^{\prime} \delta \varepsilon_{p}+q \delta \varepsilon_{q}
$$




$$
\delta W=q \delta \varepsilon_{a}
$$

Figure 6 shows the cumulative input work $(W$ ) for the natural silty-sand and base-sand specimens at three different $p^{\prime}{ }_{c}$ of $100 \mathrm{kPa}, 200 \mathrm{kPa}$ and $300 \mathrm{kPa}$, evaluated by using Eq. 3. For a given initial $p_{c}^{\prime}$, the results indicated higher input work per unit volume in the case of base-sand as compared to natural silty-sand specimens. Since all the specimens had nearly the same $e$, it ceased to capture the observed behavior. However, with the lower $e_{g}$ higher mobilised deviatoric stress at a given axial strain level caused the higher input work. It could be attributed due to the strong and higher number of sand-to-sand contacts in the base-sand specimens and could be better represented by the variations in the intergranular $e_{g}$ at $\mathrm{FC}$ lower than or near to the $\mathrm{FC}_{\text {th. }}$. Relationship of $W$ with $\varepsilon_{a}$ exhibited a more substantial difference in base-sand and silty-sand specimens at the higher confining pressure of $300 \mathrm{kPa}$. This could be due to the higher mobilized deviatoric stress and also the higher steady-state strength $\left(q_{s s}\right)$ in the case of the basesand specimen at $p_{c}^{\prime}$ to be $300 \mathrm{kPa}$. While other specimens attained very low $q_{s s}$, base-sand specimen at $300 \mathrm{kPa}$ acquired $q_{s s}$ as large as $41.1 \mathrm{kPa}$. Thus, any further incremental deformation at large strains required considerable work to be done against the $q_{s s}$ resulting into higher work input. It could be seen that specimens at $100 \mathrm{kPa}$ and $200 \mathrm{kPa}$ attained a plateau at around $8 \%$ axial strain owing to the fact that the $q_{s s}$ was nearly equal to zero. However, for specimens of natural silty-sand and base-sand at $300 \mathrm{kPa}$ the $W$ versus $\varepsilon_{a}$ relationship exhibited increasing behaviour till $25 \%$ of axial strain. Input work for base-sand specimen increased at a relatively higher rate as compared to natural silty-sand due to higher $q_{s s}$ which could be attributed to lower $e_{g}$. Cumulative input work at $\varepsilon_{a}$ to be $25 \%$ for the base-sand specimen was found to be nearly 2.45 times as that of natural silty-sand (Fig. 6).

The slope of the $W$ versus $\varepsilon_{a}$ relationship remained nearly constant for the base-sand specimen at $p^{\prime}{ }_{c}$ to be $300 \mathrm{kPa}$ indicating the specimen deforming at constant $q_{s s}$ with higher values. For specimens at $p_{c}^{\prime}$ equal to 100 $\mathrm{kPa}$ and $200 \mathrm{kPa}$, the slope of $W$ versus $\varepsilon_{a}$ relationship

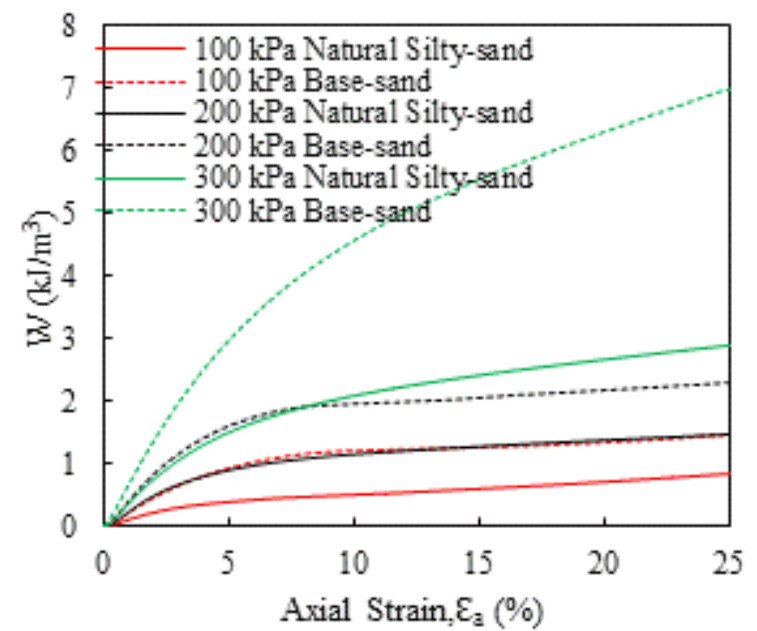

Fig. 6. Evolution of input work during undrained shearing at constant $e$ and different $e_{\mathrm{g}}$ attained a constant value of nearly zero indicating the specimens deforming at very low $(\sim 0 \mathrm{kPa})$ deviatoric stress. The slope of nearly equal to zero was indicative of zero $q_{s s}$ and hence captured liquefaction. However the amount of $W$ at which the constant slope of zero magnitude was attained increased with an increase in $p_{c}^{\prime}$ Although the specimens at constant $p_{c}^{\prime}$ had similar $e$, their $W$ versus $\varepsilon_{a}$ relationship showed very huge deviation. This aspect was better captured by large variations in $e_{g}$ for the natural silty-sand and base-sand specimens. The results indicated higher $W$ was required to deform the soils specimens at lower $e_{g}$ even though the specimens had similar $e$. This directly substantiated that inter-granular void ratio better represented the mechanical behaviour of granular mixtures.

\section{Conclusions}

Following conclusions were drawn from the study:

1. At a similar void ratio $(e)$ but different intergranular void ratio $\left(e_{g}\right)$, volume compressibility $\left(m_{v}\right)$ of natural silty-sand specimens was found to be more than 1.5 times as that of base-sand specimens. Therefore, $m_{v}$ of granular mixes was observed to be dependent on $e_{g}$ rather than the global void ratio $(e)$. This could be due to the fact that $e_{g}$ assumed that the small silt particles as voids with no contribution to force chain network which was more closer to the realistic behaviour at $\mathrm{FC}$ equal to or less than $\mathrm{FC}_{\text {th }}$.

2. Undrained shear strength behavior of sand-silt mixtures with $\mathrm{FC}$ less than or near to $\mathrm{FC}_{\text {th }}$ was better represented by taking state parameter as a function of $e_{g}$. At similar $e$, the peak deviatoric stress increased with the decrease in $e_{g}$. Instead of $e$, undrained fragility was found to be strongly dependent on $e_{g}$ as it directly correlated with the number of collapsible contacts.

3. Rapid and large excess pore water pressure response during the very early stages of deformation was observed to have a strong dependence on the metastable inter-particle structure of granular mixes. The degree of such soil fabric was better captured by $e_{g}$ as compared to $e$.

4. The amount of input work done in deforming specimens with a similar void ratio $(e)$ and the different inter-granular void ratio $\left(e_{g}\right)$ indicated that the resistance to the external load was better associated to $e_{g}$ rather than to $e$.

\section{References}

1. G. Castro. Liquefaction of sands. Ph.D. Thesis, Harvard Soil Mech. (1969).

2. K. Been, M.G. Jefferies. A state parameter for sands. Géotechnique, 35(2) 99-112 (1985).

3. P.V. Lade, J.A. Yamamuro. Effects of nonplastic fines on static liquefaction of sands. Can. Geotech. J., 34(6) 918-928 (1997). 